\title{
Microstructure Investigations of Powders and Additive Manufactured Parts
}

\author{
M. Albu' ${ }^{1}$, S. Mitsche ${ }^{2}$, M. Nachtnebel' ${ }^{1}$ R. Krisper ${ }^{1}$, M. Dienstleder ${ }^{1}$, H. Schröttner ${ }^{2}$, and G. Kothleitner ${ }^{2}$
}

${ }^{1}$ Graz Centre for Electron Microscopy, Austrian Centre for Electron Microscopy and Nanoanalysis, Graz, Austria Institute for Electron Microscopy and Nanoanalysis, University of Technology, Graz, Austria

Received February 4, 2020; accepted February 6, 2020; published online February 25, 2020

\begin{abstract}
This paper presents an advanced microstructural analysis of the AISiMg, Ti64, and N700 powders used for additive manufacturing. The internal microstructure of the regular and irregular powder grains were characterized down to atomic resolution by using scanning electron microscopy and high resolution scanning transmission electron microscopy.

The accretionary forms on top of the irregular AISiMg powder grains exhibit a slightly coarse microstructure with a network of eutectic Si consisting of nano-crystallites, suggesting a slower cooling than the grain itself that contain a predominately amorphous Si network.

A $\mathrm{nm}$ thin amorphous $\mathrm{C}$ layer on the surface of some Ti64 plasma atomized powder grains promoted the attachment of satellites and growth of envelopes. In case of gas atomized N700 powder grains, we identified thin oxide and carbon amorphous layers as well as metal segregations at the interface between the grain body and the accretionary forms.
\end{abstract}

Keywords: Powder, AISiMg, Ti64, N700, Microstructure, High-resolution transmission electron microscopy

\section{Mikrostrukturuntersuchungen von Pulvern und additiv hergestellten Bauteilen}

Zusammenfassung: In diesem Artikel wird eine umfassende Mikrostrukturanalyse der AISiMg-, Ti64- und N700-Pulver vorgestellt, welche für die additive Fertigung verwendet werden. Die innere Mikrostruktur der regelmäßigen und unregelmäßigen Pulverkörner wurde unter Verwendung von Rasterelektronenmikroskopie und hochauflösender Rastertransmissionselektronenmikroskopie bis zur atomaren Auflösung charakterisiert.

M. Albu ( $\varangle)$

Graz Centre for Electron Microscopy,

Austrian Centre for Electron Microscopy and Nanoanalysis, Steyrergasse 17,

8010 Graz, Austria

mihaela.albu@felmi-zfe.at
Die Anlagerungsformen auf den unregelmäßigen AlSiMg-Pulverkörnern weisen eine leicht grobe Mikrostruktur mit einem Netzwerk aus eutektischem Si-Nanokristalliten auf. Diese Anwesenheit der Si-Nanokristallite deutet auf eine langsamere Abkühlung als des Korns hin, welches ein überwiegend amorphes Si-Netzwerk enthält.

Die Entstehung der Anlagerungen und Anhaftung von Sateliten wurde durch eine nanometerdünne amorphe C-Schicht auf der Oberfläche einiger Ti64-Pulverkörner gefördert. Für die N700-Pulverkörner wurden dünne Oxidund amorphe C-Schichten sowie Metallseigerungen an der Grenzfläche zwischen dem Kornkörper und den Anlagerungsformen identifiziert.

Schlüsselwörter: German: AISiMg, Ti64, N700,

Mikrostruktur, Hoch-auflösende

Transmissionselektronenmikroskopie

\section{Introduction}

The mechanical properties, static, and dynamic of the final additive manufactured part are governed by several inputs and parameters that affect the microstructure of the printed part. Since most common systems used for additive manufacturing (selective laser melting and electron beam melting) use metal powders as feedstock, their characterization is of central importance. The quality of the powder is determined by size, surface morphology, composition, and amount of internal porosity. Old and recycled metal powders tend to oxidize and collect moisture when exposed to air. Therefore, the built chamber atmosphere should contain a shield gas. These gases, however, may affect the chemistry, processability, and the heat transfer, which, in turn, affects the microstructure of the printed part [1-4].

Whereas the chemical composition, size, surface morphology, and internal porosity have been well characterized by the producers, less attention has been given to the internal microstructure of the powder grains and the cause 

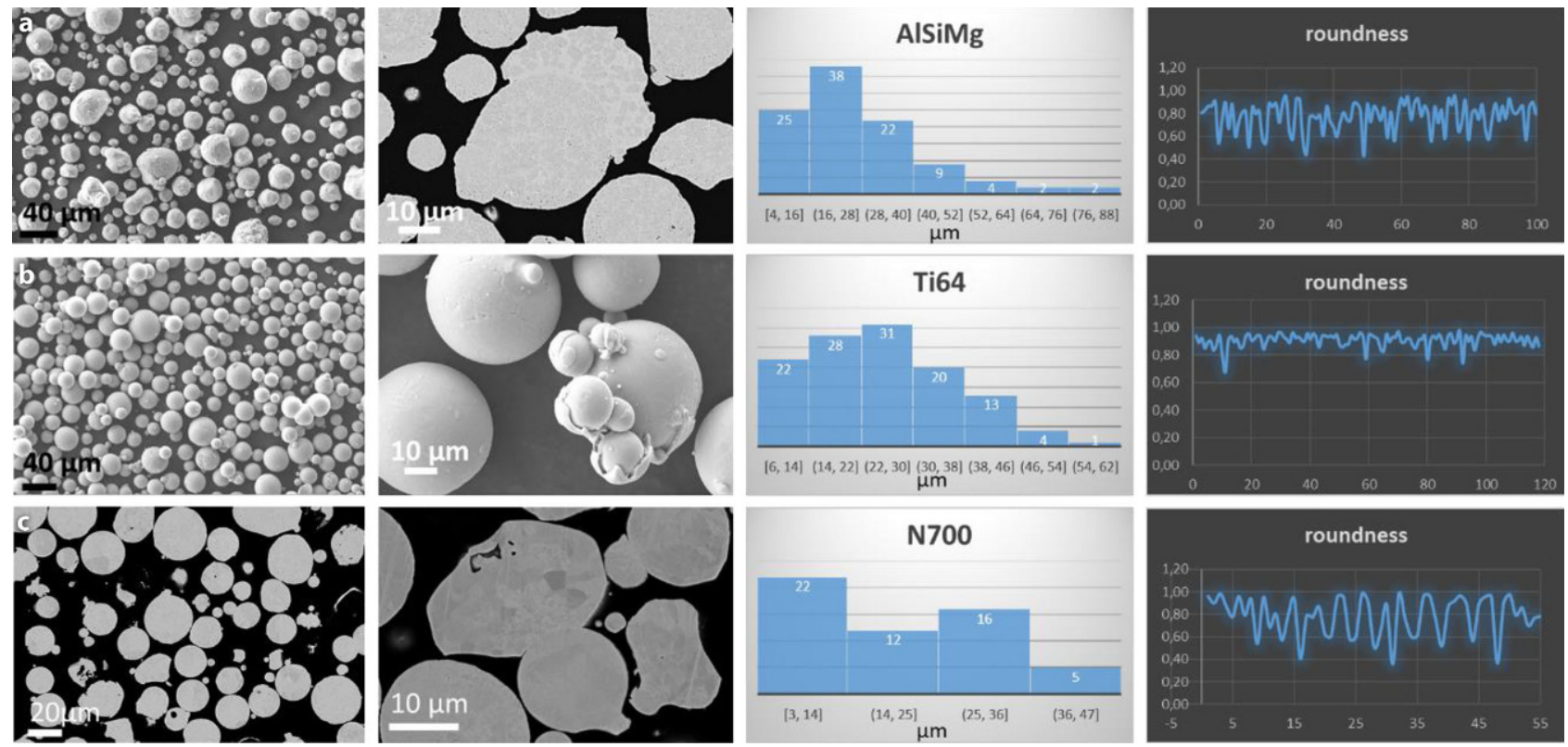

Fig. 1: SEM images, size distributions, and roundness of the AISi10Mg (top row), Ti64 (middle row), and N700 powders (bottom row)

of irregularities on the surface of the grains (satellites and accretionary forms or envelopes) [5].

This paper attempts to provide insights into the origin of the irregularities and changes in the internal microstructure of the powder grains, highlighting the importance of powder quality to the microstructure of the final part.

\section{Materials and Methods}

The AISi10Mg, Ti64, and N700 powder grains were first dispersed on an adhesive tape and investigated in the scanning electron microscope (SEM). Additionally, the powder was embedded in a resin (CALDOFIX), polished down to a couple of tents of micrometres and thinned by $\mathrm{Ar}$-ion milling at cryogenic temperature. For EBDS measurements, the embedded grains were polished by using diamante and aluminium suspensions as final polishing steps.

Scanning transmission electron microscopy (STEM) investigations have been performed on focused in beam (FIB) prepared lamellae cut out of the regular powder grains and grains with satellites and accretionary forms. For the in-situ heating experiment, the lamella was mounted on a MEMS heating chip (DENS solutions-Wildfire $\mathrm{H}+\mathrm{DT}$, heating/quench rate $200^{\circ} \mathrm{C} / \mathrm{ms}$ and settling time $2 \mathrm{~s}$ ).

The additive manufactured samples presented in this work were built by using the SLM method. The samples for SEM investigations were cut and polished along (z-axis) and perpendicular ( $x y$-plan) to the build axis.

SEM micrographs were acquired by using backscattering, secondary electron and in-lens detectors. For the analytical and crystallographic investigations of the grains and grain boundaries, dispersive $X$-ray spectrometry and EBSD were involved.
High-resolution STEM investigations were carried out by using the FEI Titan G3 60-300 at a beam voltage of $300 \mathrm{kV}$. The advanced instrumentation fitted to this microscope allows for recording HR-STEM images with annular dark field (ADF), annular bright field (ABF), and high angle annular dark field (HAADF) detectors. The detection of the chemical composition of different phases was performed by using energy dispersive X-ray analysis (EDX) and electron energy loss spectroscopy. For the energy dispersive $\mathrm{X}$-ray analysis, the microscope is equipped with a FEI Super-X windowless silicon drift detector (Chemi-STEM technology), and, for the electron energy loss spectroscopy, the setup includes a Dual EELS Quantum Gatan Imaging Filter (GIF) [6].

\section{Experimental Results}

The morphology, chemical composition, and particle size of the powders were first characterized in the scanning electron microscope (SEM). Fig. 1 shows the micrographs of the AISi10Mg, Ti64, and N700 powder grains, their size distribution, and roundness factor. Some grains contain some $\mu \mathrm{m}$-large but also $\mathrm{nm}$-sized pores. We observed a rather large size distribution and a high amount of satellites in the gas-atomized powders (AISiMg and N700).

Therefore, such grains with satellites and accretionary forms were investigated by STEM. We observed that, regardless of alloy composition and production, a nm-thin layer of amorphous Carbon is present at the interface between the particle and the irregularities.

In case of the Al-alloy, the microstructure of the accretionary form is coarser than the microstructure of the grain body indicating slower cooling. Therefore, the eutectic Si in the accretionary form is mostly nano-crystalline, while, in the grain body, it is mostly amorphous. Fig. 2a presents 

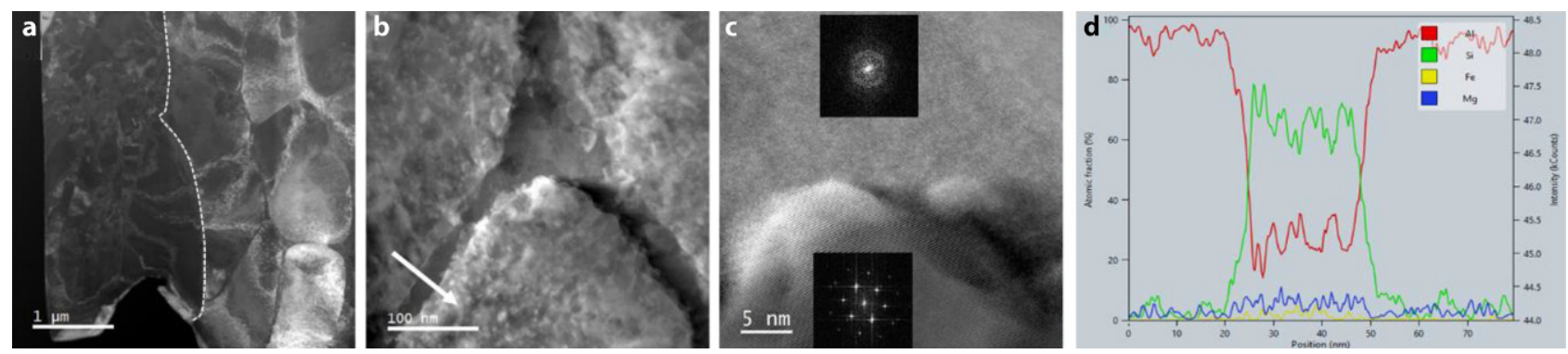

Fig. 2: a STEM ADF image of the FIB lamella cut from an irregular powder grain, dotted line denotes the interface between grain body (left) and accretionary form (right); b higher magnification STEM ADF image of the Si network; c atomic resolution image of the amorphous eutectic Si. Insets show the FFT of the amorphous $\mathrm{Si}$ and the $\alpha$-Al crystalline regions. $d$ EDX element profile along the arrow in (b)

Fig. 3: EBSD images of $\mathbf{a} \alpha$-phase and $\mathbf{b} \beta$-phase
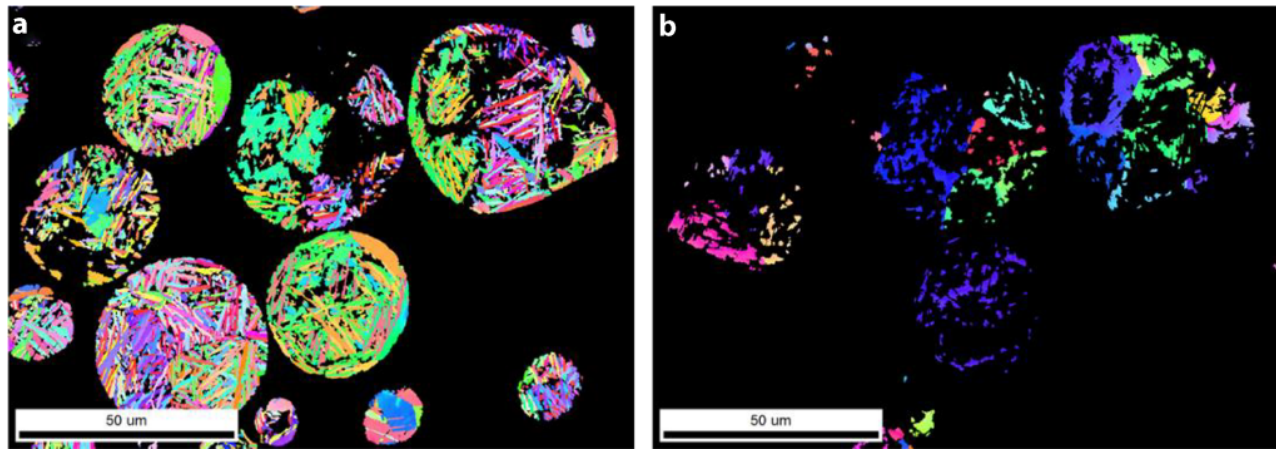

the FIB lamella cut from an irregular powder grain, with the dotted line denoting the interface between the grain body and accretionary form. Fig. 2b, c show the eutectic $\mathrm{Si}$ in the grain body at a higher magnification and at an atomic resolution, with the insets on $2 \mathrm{c}$ being the Fourier transform of the amorphous $\mathrm{Si}$ and crystalline $\alpha$-Al. The chemical composition of the eutectic Si network along the arrow on Fig. $2 \mathrm{~b}$ is presented in Fig. $2 \mathrm{~d}$. Nanometre-sized $\mathrm{Si}(\mathrm{Mg})$ particles were also dispersed all over the Al matrix. This microstructure is generated by the high cooling rates during the gas atomisation process. In-situ heating measurements performed on FIB lamella revealed the temperature at which the amorphous Si starts to form nanocrystallites to be $140^{\circ} \mathrm{C}$. A full nano-crystallization of the $\mathrm{Si}$ network was achieved at $350^{\circ} \mathrm{C}$. With a further increase of the temperature, the Si network became coarse globular and monocrystalline.

The as printed sample showed a similar fine microstructure with a nano-crystalized eutectic $\mathrm{Si}$ and nanometresized Fe segregations dispersed in the Si network. Moreover, $\mathrm{Si}(\mathrm{Mg})$ nanoparticles of about $5-10 \mathrm{~nm}$ were dispersed in the Al matrix. Similar observations have been made in other AISi alloys [7, 8]. Fe-rich intermetallic phases were also observed at the boundary of the $\alpha$-Al cells, intermixed within the Si network.

In order to observe the statistic distribution of the $\alpha$ - and $\beta$-phases within the plasma atomized Ti64 powder grains, we performed EBDS measurements. The images in Fig. $3 a$, b show the $\alpha$ - and the $\beta$-phase respectively. Some powder grains appear to not contain $\beta$-phase (probably in the $\mathrm{nm}$ range and therefore not detectable in SEM), whereas in others their fraction is very high.
The microstructure of the powder grains consists mainly of $\alpha$ - and $\beta$-phases. By using STEM on FIB lamella, however, we identified, besides the $\beta$-phase with about 12.5 at $\%$ of $\mathrm{V}$, small vanadium rich regions with a size of about $50 \mathrm{~nm}$ (Fig. 4a) and a ratio Ti/V of 1.5 (Fig. 4b), which were assigned to the $\omega$-phase.

The SEM image of an irregular grain in the Ti64 powder, from which a FIB lamella was cut, is presented in Fig. $5 a$, b. Fig. $5 \mathrm{c}$ shows the STEM HAADF image of the lamella, and $5 \mathrm{~d}$ and $5 \mathrm{e}$ present higher magnification STEM images at the interface between the grain body and envelope. $\mathrm{Ti}, \mathrm{O}$, and CEELS elemental maps are presented in $5 \mathrm{~d}$, and the $\sim 20 \mathrm{~nm}$ amorphous $\mathrm{C}$ layer along the interface is also shown on the HR TEM image as an inset of Fig. 5e. The EELS chemical analysis of the amorphous layer on top of the particle situated between grain body and envelope indicates regions of amorphous $\mathrm{TiO}_{2}$ and amorphous $\mathrm{C}$.

The as printed sample exhibits a fine microstructure consisting of acicular $\beta$-phase mixed with a fine-lamellar $\alpha$-phase, as observed on the SEM and EBSD images in Figs. 6 and 7. The chemical composition of the V-rich phase in Fig. $5 b$ detected by EDX shows concentrations of $16-18 w t \%$ of $\mathrm{V}, 4.5-4 \mathrm{wt} \%$ of $\mathrm{Fe}$, and $4.2-5.4 \mathrm{wt} \%$ of Al. The $\beta$-phase (Fig. 7b) with dimensions between $200 \mathrm{~nm}$ and $6 \mu \mathrm{m}$ is evenly distributed all over the sample, with its fraction in the as printed sample being about $3 \%$. At such a high cooling rate, the $\alpha$-phase lamellae are, as expected, partially basket-like arranged.

The N700 powder was produced by gas atomization (BÖHLER N700 AMPO [9]). As observed in Fig. 1 bottom row, the powder presents a low roundness factor with a large size distribution $(14-45 \mu \mathrm{m})$ [10]. 

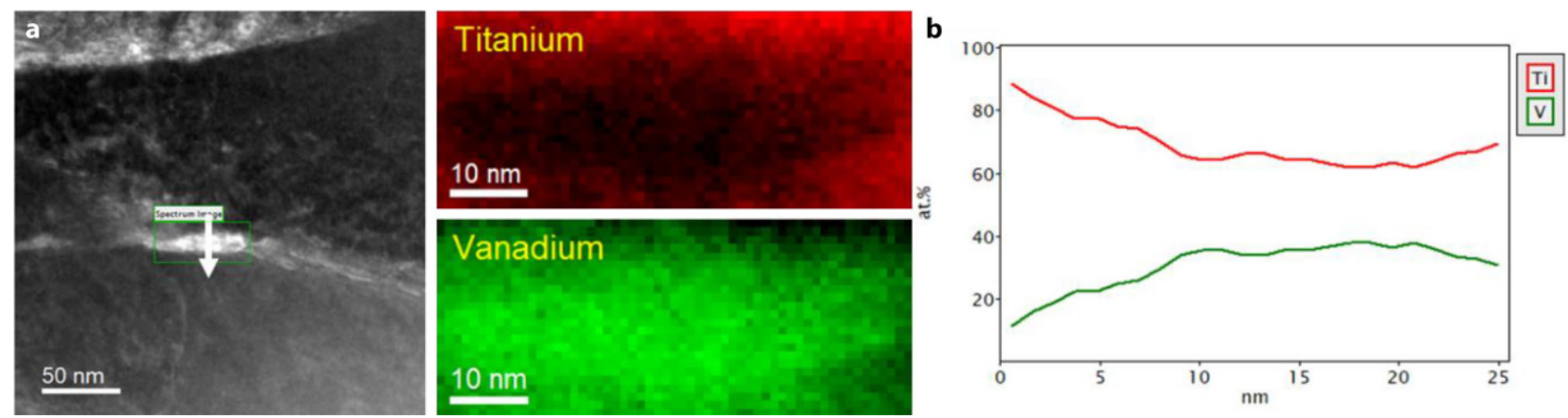

Fig. 4: a STEM HAADF image of a lamella cut out from a regular Ti64 powder grain containing $\omega$-phase and the EELS chemical maps of $V$ and Ti. b EELS element profile along the arrow drown on the investigated area showing the high content of $\mathrm{V}(\sim 40$ at $\%)$
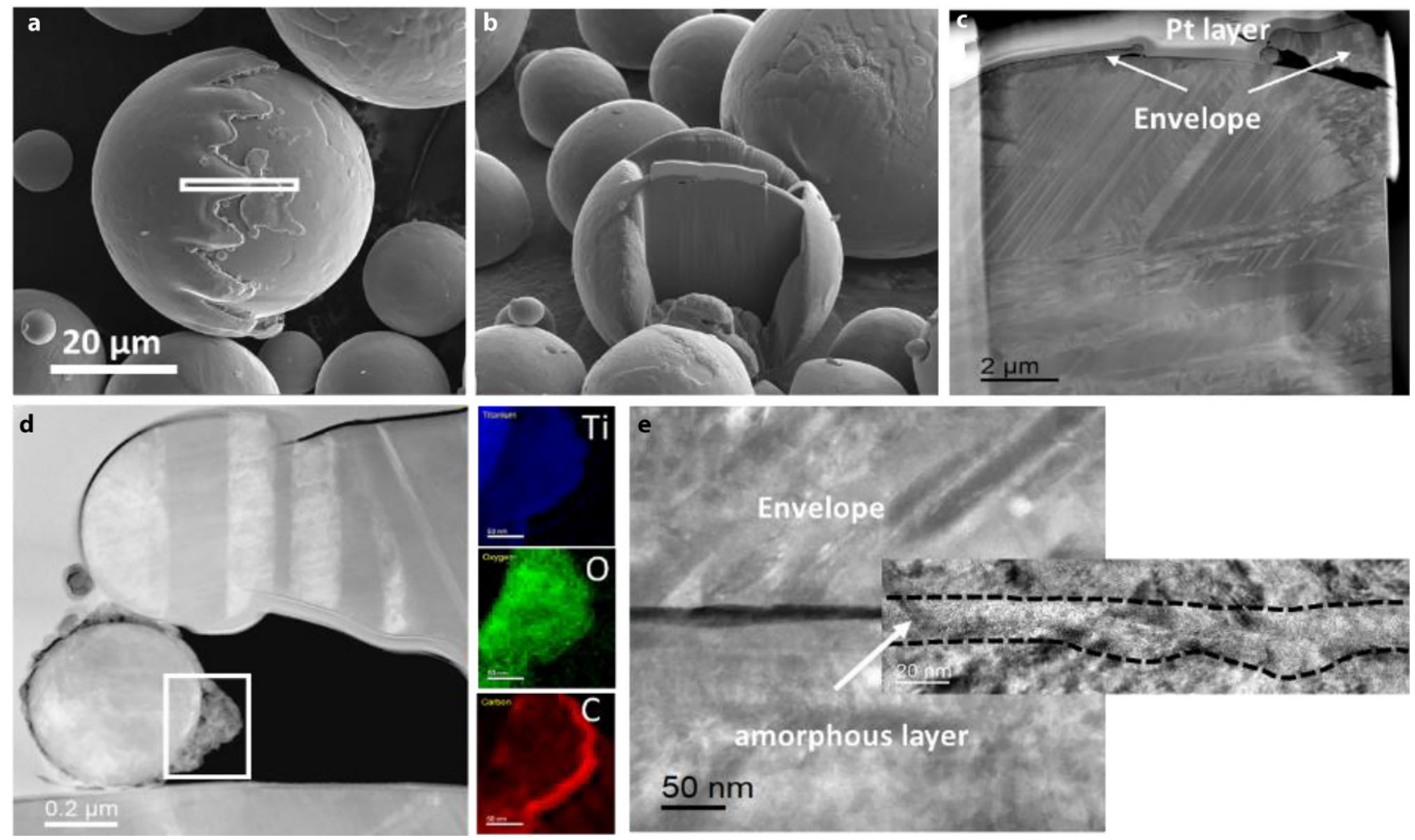

Fig. 5: a SEM image of an irregular Ti64 powder grain from which the FIB lamella in $\mathbf{b}$ was cut. c STEM HAADF image of the lamella indicating the particle body and the envelope as well as the Pt layer deposited during the FIB process; $\mathbf{d}$ higher magnification STEM HAADF image of the particle incorporated into the envelope and the chemical analysis (EELS maps) of the amorphous layer on top of it. e high magnification STEM image of the interface between grain body and envelope with a high-resolution TEM image of the amorphous Carbon as inset
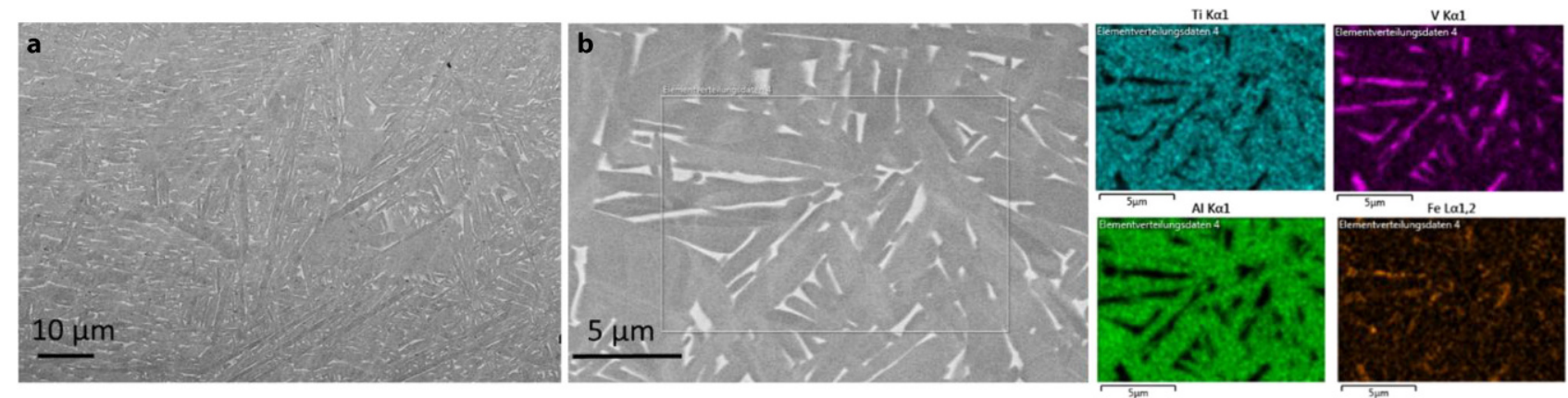

Fig. 6: SEM images at a low and $\mathbf{b}$ higher magnification together with the EDX chemical analysis of the as-built Ti64 sample 
Fig. 7: EBSD images of the as-built Ti64 sample (build axis): $\mathbf{a} \alpha$-phase and $\mathbf{b} \beta$-phase
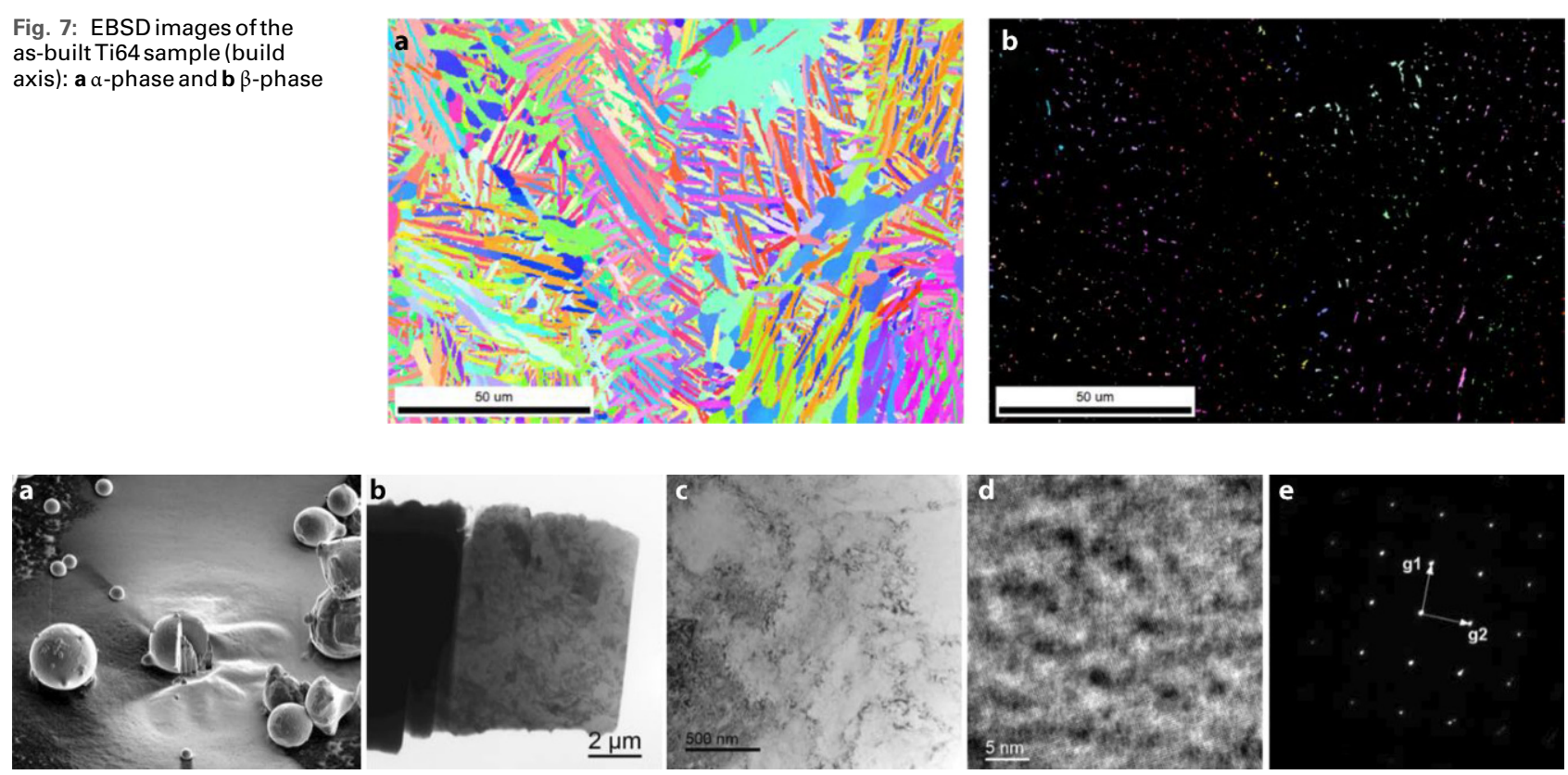

Fig. 8: a SEM image of a regular N700 powder grain from which the lamella in b was cut. chigher magnification TEM zero loss filtered image of the lamella in (b); $\mathbf{d}$ high resolution TEM image from the lamella; e SAED electron diffraction image from the region in $\mathbf{c}$ with $\mathrm{d}_{1}=\mathrm{d}_{2}=0.2885 \mathrm{~nm}$

The intrinsic microstructure of a regular powder grain (Fig. 8) is homogenous with no nanometre-sized precipitates, and the electron diffraction investigation (Fig. 8e) indicates the structure of the $\alpha$-ferrite (bcc) with a lattice parameter of $0.2885 \mathrm{~nm}$. The lattice parameter of $\alpha$-ferrite in powders can increase from 0.2866 up to $0.29199 \mathrm{~nm}$ with increasing temperature as described in literature [11].

The analysis of a lamella cut out of an irregular grain in the N700 powder revealed two different amorphous layers at the interface between the grain body and envelope: oxygen (iron oxide with a thickness of about $10 \mathrm{~nm}$ ) and carbon $(5-8 \mathrm{~nm})$, but also a metallic $\mathrm{Cu}$ layer with a thickness of around $10 \mathrm{~nm}$. The Cu segregation is rather unexpected but not impossible, since the alloy contains $3-5 \mathrm{wt} \%$ of $\mathrm{Cu}$ and the cooling rate during production is very high.

\section{Conclusions}

The understanding of microstructure change and evolution, correlated with the desired mechanical properties of the as-fabricated AM parts, is strongly linked with the feedstock quality and AM process parameters. In order to reduce production and post-processing costs, powder characteristics and effects that might influence its quality, and therefore the quality of the as fabricated part, have to be well understood. Here we presented detailed analyses of the internal microstructure of powder grains and the reason for irregularities on their surface.

The microstructure of the AISiMg grains contains ultrafine cellular a-Al structures with a network of eutectic silicon predominantly amorphous in the gas-atomized powder. A partial nano-crystallization of the amorphous silicon was observed during the in-situ heating experiment starting with $140^{\circ} \mathrm{C}$ and reaching the full crystallization at $350^{\circ} \mathrm{C}$.
The accretionary forms on the surface of the powder grains present a slightly coarser microstructure with a crystalline Si network, suggesting a slower cooling during the time of flight.

The Ti64 grains show a higher roundness factor, although satellites and envelopes are also attached to the surface of some grains. Their existence seems to be linked to the presence of a $20 \mathrm{~nm}$ amorphous C layer, situated at the interface between the satellites and envelopes with the grain body. The microstructure consists of $\alpha$ - and $\beta$-phases, which are statistically distributed within the grains, but a sporadic occurrence of the $\omega$-phase was also confirmed.

The satellites and accretionary forms are numerous in the N700 powder and linked to the presence of an amorphous oxygen layer with a thickness of $10 \mathrm{~nm}$ and an amorphous carbon layer with a thickness of $5 \mathrm{~nm}$, at the interface with the grain body. Moreover, metal segregations such as Cu could also be found.

Acknowledgements. We gratefully acknowledge our project partners Mr. B. Panzirsch and Mr. G. Schindelbacher from ÖGI, Leoben, Austria, for sample provision.

Funding. Open access funding provided by Graz University of Technology.

Open Access This article is licensed under a Creative Commons Attribution 4.0 International License, which permits use, sharing, adaptation, distribution and reproduction in any medium or format, as long as you give appropriate credit to the original author(s) and the source, provide a link to the Creative Commons licence, and indicate if changes were made. The images or other third party material in this article are included in the article's Creative Commons licence, unless indicated otherwise in a credit line to the material. If material is not included in the article's Creative Commons licence and your intended use is not permitted by statutory regulation or exceeds the permitted use, you will need to obtain permission directly from the copyright holder. To view a copy of this licence, visit http://creativecommons.org/licenses/by/4.0/. 


\section{References}

1. W. J. Sames, W. J.; F. A. List, F. A.; S. Pannala, S.; R. R. Dehoff R. R; \& S. S. BabuS. S.: The metallurgy and processing science of metal additive manufacturing, Int. Mat. Rev., (2016), pp 315-360 https:// www.tandfonline.com/doi/full/10.1080/09506608.2015.1116649

2. Tang, H. P.; Qian, M.; Liu, N.; Zhang, X. Z.; Yang, G. Y.; Wang, J.: Effect of Powder Reuse Times on Additive Manufacturing of Ti-6Al4V by Selective Electron Beam Melting, JOM (2015), pp 1-9

3. Slotwinski, J. A.; Garboczi, E. J.; Stutzman, P. E.; Ferraris, C. F.; Watson, S. S.; Peltz, M. A.: Characterization of Metal Powders Used for Additive Manufacturing. J Res Natl Inst Stand Technol., 119 (2014), pp460-493

4. Chen, B.; Moon, S. K.; Yao, X.; Bi, X.; Shen, J.; Umeda, J.; Kondoh, K.: Strength and strain hardening of a selective laser melted AISi10Mg alloy. Scripta Mater, 141 (2017), pp 45-49

5. Zhou, L.; Mehta, A.; Schulz, E.; McWilliams, B.; Cho, K.; Sohn, Y.: Microstructure, precipitates and hardness of selectively laser melted AISi10Mg alloy before and after heat treatment. Mat. Charact., 143 (2018), pp 5-17

6. Gubbens, A.; Barfels, M.; Trevor, C.; Twesten, R.; Mooney, P.; Thomas, P.; Menon, N.; Kraus, B.; Mao, C.; McGinn, B.: The GIF Quantum, a next generation post-column imaging energy filter, Ultramicroscopy, 110 (2010), pp 962-970
7. Liu, M.; Fu, H.; Tian, L.; Xiao, W.; Peng, Q.; Ma, V.: Nucleation and growth mechanisms of nano-scaled Si precipitates in Al-7Si supersaturated solid solution, Materials and Design, 121 (2017), pp 373-382

8. Li, X. P. Ji, G.; Chen, G.; Addad, A.; Wu, Y.; Wang, H. W.; Vleugels, J.; Van Humbeeck, J.; Kruth, J. P.: Selective laser melting of nano-TiB2 decorated AISi10Mg alloy with high fracture strength and ductility, Acta Mater., 129 (2017), pp 183-193

9. voestalpine BÖHLER Edelstahl GmbH \& Co KG, BÖHLER N700 AMPO Product Data Sheet, 2018

10. Turk, C.; Zunko, H.; Aumayr, C.; Leitner, H.; Kapp, M.: Advances in Maraging Steels for Additive Manufacturing, Berg Huettenmaenn Monatsh, 164 (2019), no. 3, pp 112-116, https://doi.org/10.1007/ s00501-019-0835-z

11. Feng, Z. Y.: The lattice parameter of gamma Iron and Iron chromium alloys, Master Thesis, Dept. Mat. Sci and Eng., Case Western Reserve University, 2015

Publisher's Note. Springer Nature remains neutral with regard to jurisdictional claims in published maps and institutional affiliations. 